\title{
Explorando a Arqueologia: um projeto educativo no Engenho São Jorge dos Erasmos
}

\author{
Elaine Farias Veloso Hirata* \\ Judith Mader Elazari** \\ Jussara Moritz*** \\ André Costa*** \\ Silvio Cordeiro*****
}

HIRATA, E.F.V.; ELAZARI, J.M.; MORITZ, J.; COSTA, A.; CORDEIRO, S. Explorando a Arqueologia: um projeto educativo no Engenho São Jorge dos Erasmos. Revista do Museu de Arqueologia e Etnologia, São Paulo, 17: 419-433, 2007.

Resumo: Este artigo descreve o programa de ação educativa desenvolvido junto ao Engenho São Jorge dos Erasmos, Santos-SP, um sítio arqueológico colonial, e estabelece as premissas metodológicas que nortearam este trabalho.

Palavras-chave: Engenho São Jorge dos Erasmos - Arqueologia e Educação Videodocumentário e Educação - Brasil Colonial - Açúcar.

\section{Breve histórico das ruínas}

$\mathrm{V}$ elhas paredes de pedra e cal, muros, alicerces... Quatro séculos depois, pouco restou do conjunto arquitetônico quinhentista situado na cidade litorânea de Santos, considerado o remanescente de uma das primeiras manufaturas de açúcar implantadas no Novo Mundo. As ruínas do Engenho São

(*) Museu de Arqueologia e Etnologia da Universidade de São Paulo. Arqueóloga. ehirata@usp.br

$\left.{ }^{* *}\right)$ Museu de Arqueologia e Etnologia da Universidade de São Paulo. Serviço Técnico de Musealização, Área de Educação.judimel@usp.br

$\left.{ }^{(* * *}\right)$ Historiadora e educadora. jumoritz@sunmoritz.com $\left.{ }^{* * * *}\right)$ Fundação Armando Álvares Penteado-FAAP. Cineasta e documentarista. andre@olharperiferico.com.br ${ }^{* * * * *}$ ) Museu de Arqueologia e Etnologia da Universidade de São Paulo. Arquiteto e documentarista, mestrando em arqueologia (MAE-USP).silvio@olharperiferico.com.br
Jorge dos Erasmos estão entre as nossas mais antigas construções coloniais, contemporâneas do início do povoamento meridional das terras do Brasil por Martim Afonso de Souza, em sua Capitania e por ele nomeada de S. Vicente (Foto 1).

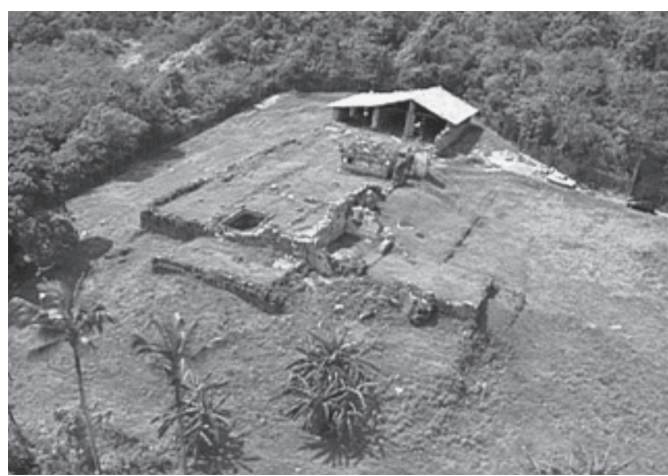

Foto 1. Vista aérea das ruínas do Engenho São Jorge dos Erasmos, zona noroeste da cidade de Santos. Imagem: Silvio Cordeiro. 
Sabe-se que o capitão-donatário trouxera da Ilha da Madeira as primeiras mudas de cana e os mestres entendidos na produção do açúcar: o estabelecimento de engenhos em S. Vicente foi, como haveria de ser, muito incentivado, posto a crescente demanda e lucro que se obtinha pelo comércio açucareiro nos mercados da Europa. Nos termos da colonização, a implantação de engenhos conjugava fatores fundamentais como a posse territorial e a produção - de caráter manufatureiro-comercial - articulada a interesses de mercadores europeus no comércio transatlântico, que impulsionaria outro importante mercado: a escravidão negra.

O próprio Martim Afonso constituiu um engenho, junto a outros sócios, entre eles, seu irmão Pero Lopes de Souza e o flamengo Johan Van Hielst, representante em Lisboa da casa mercantil da família Schetz, de Antuérpia. Fundaram, assim, o chamado Engenho São Jorge, também conhecido como Engenho do Governador. Pouco tempo depois, após a ida de Martim Afonso para as Índias, tal empresa é adquirida, em torno de 1540 , pelo banqueiro e mercador flamengo Erasmus Schetz.

Sua história, de situação exemplar no quadro das estratégias do início da ocupação efetiva e exploração econômica do Brasil, permanece ainda pouco conhecida, o que motivou em grande parte a retomada das escavações arqueológicas no sítio histórico das ruínas, em $1996 .{ }^{1}$

Em 2001, no contexto do projeto arqueológico do Museu de Arqueologia e Etnologia da USP intitulado Engenho São Jorge dos Erasmos: Estudos de Arqueologia da Paisagem ${ }^{2}$ constituiu-se o módulo educativo intitulado Arqueologia, Patrimônio e Ação Educativa, a ser realizado na EPSG Profa. Gracinda Maria Ferreira, vizinha do monumento quinhentista em Santos. Tal ação, seu conceito, objetivos e possibilidades formam o conteúdo deste artigo, como veremos adiante.

(1) Estas escavações foram coordenadas pela Profa. Dra. Margarida Davina Andreatta 1996.

(2) Projeto com financiamento da FAPESP (Processo 00/ 03451-3), coordenado pelo Prof. Dr. José Luiz de Morais, do Museu de Arqueologia e Etnologia da USP.

\section{Um projeto educativo junto ao Engenho: fundamentos}

\section{i. Aprender com as coisas?}

Por que aprender com as coisas? Qual seria a relação entre Arqueologia e Educação? Na origem de nossa proposta, e de maneira ampla, foram estas as questões que dirigiram o projeto na busca de uma perspectiva inovadora no exercício (sempre desafiador) das relações entre educar e aprender.

Os seres humanos usam os objetos como um meio de compreender e explicar o mundo: as coisas evocam pessoas e situações, provocam emoções e suscitam reações de toda natureza. $\mathrm{O}$ fazem porque, enquanto objetos, são suportes materiais para mensagens e informações, são signos e símbolos permeando nosso cotidiano, mediando as relações sociais, comunicando hierarquias e classificações, explicitando "pertencimentos" e exclusões, mobilizando ações de toda natureza. Neste sentido, a habilidade para interpretá-los auxiliará sobremaneira na compreensão do mundo.

Pode-se afirmar, enfim, que objetos materiais são tão significantes quanto as palavras para descrever uma sociedade e a Arqueologia ao constituir-se na principal disciplina a investigar as sociedades humanas a partir da ótica dos vestígios materiais remanescentes, terá uma contribuição significativa a dar a uma prática pedagógica centrada na exploração do mundo das coisas.

O sistema educativo contemporâneo, no entanto, parece ignorar o universo material em que o homem está imerso e tem direcionado o processo pedagógico para o universo das palavras: professor e aluno têm no discurso falado e escrito - a principal forma de ensinar e aprender. Cria-se, assim, uma dicotomia entre a vivência do homem, entre coisas e palavras, e o ensino escolar, que dá conta apenas de uma dimensão da realidade. E o que significaria introduzir a esfera da vida material na dinâmica da aprendizagem?

No nível mais simples de observação tratase de tornar disponível o concreto, seja um ou 
um conjunto de objetos, uma edificação, qualquer produto do trabalho humano para atuar como núcleo catalisador da aprendizagem. Inverter a ênfase do processo educacional do abstrato para o concreto que, por sua vez, ao ser devidamente explorado, acaba por levar à abstração. Mas como ir do resíduo material deixado por uma sociedade para uma compreensão de sua dinâmica, de seus meios de sobrevivência aos seus produtos artísticos, sua maneira de ver o mundo, seus comportamentos religiosos?

$\mathrm{Na}$ sala de aula, a partir do manuseio orientado e problematizado de um conjunto de artefatos e da constituição de dados a respeito deles (matéria-prima, técnica de produção, função) é possível ir construindo um discurso hipotético sobre a sociedade que os produziu, utilizou e posteriormente os descartou. $\mathrm{O}$ mesmo percurso metodológico poderá ser experimentado diante de uma estrutura arquitetônica ou de um espaço na paisagem que tenha sofrido a ação do trabalho humano. Podemos, como os arqueólogos procedem no seu cotidiano, entrelaçar estas diversas categorias de coisas materiais: o objeto no edifício e este na paisagem. Teremos aí então uma hipótese, um modelo a ser aplicado a uma situação histórica precisa.

Desta forma, são os alunos que vão constituindo o corpo de informações, auxiliados, é claro, pelos orientadores do trabalho. Propicia-se, assim, a vivência, a experimentação do processo investigativo do arqueólogo. Notese bem que não estamos descrevendo ou contando como o arqueólogo trabalha e sim colocando o aluno na posição deste especialista. Propiciando uma experiência singular e motivadora, a da descoberta, a de sentir-se capaz de aprender e criar desde que os instrumentos necessários sejam fornecidos (Hirata et al. 1989).

No caso, por exemplo, do monumento Engenho dos Erasmos, pode-se partir da edificação em si, observando e descrevendo-a do ponto de vista do material utilizado e das técnicas de construção, passando para a organização dos espaços internos especializados em função da produção do açúcar e de outras finalidades para, por fim, promover a inserção do Engenho, enquanto ambiente construído, na paisagem.

Em cada um desses passos caberá ao professor conduzir o processo de descoberta dos diversos níveis de informação contidos, no caso, na edificação, de forma que os alunos possam ir recuperando, neste documento material, as assinaturas que registram as técnicas de fabricação, o uso/função e eventualmente o abandono ou descarte. Tais dados serão posteriormente complementados com pesquisa bibliográfica e iconográfica, na busca de contextualização do documento.

Paralelamente à coleta de dados serão pensadas hipóteses para a interpretação das questões que naturalmente irão se apresentando. No decorrer deste processo o aluno se vê colocado na posição de produtor de conhecimento, instigado a descobrir e buscar respostas. A exploração do objeto ou do edifício, envolverá conhecimentos diversificados evidenciando uma outra importante vertente deste trabalho: a integração das disciplinas. No exemplo acima se percebe claramente como história, geografia, ciências, matemática, educação artística e português poderão articular-se, promovendo a interação de conteúdos e imprimindo um caráter dinâmico à aprendizagem.

Assim, o fazer, os experimentos, podem ser reconhecidos como caminhos facilitadores do conhecer, do saber, a vivência do concreto como estratégia pedagógica com potencial motivador. O manuseio e a exploração - em resumo, a descoberta do objeto - podem ser formas alternativas de aprendizagem, atraindo crianças e adultos de uma forma que dificilmente outros métodos o conseguiriam.

Os objetos propiciam uma experiência concreta que auxilia e esclarece o pensamento abstrato; também favorecem estímulos criativos, instigam respostas que tocam o sensível e a emoção, aguçam a percepção para as artes. Constituem-se em exemplos de como idéias e sentimentos podem ser expressos em outras formas além das palavras. As relações "passado e presente", "nós e os outros", são mais facilmente discutidas e compreendidas se partimos da interpretação do mundo material construído por diferentes sociedades. 


\section{ii. Aprender com as coisas pode significar aprender a aprender?}

Aprender com o universo das coisas, produto da interação homem-ambiente-sociedade, significa vivenciar um processo particular de construção do conhecimento. É partir de uma realidade concreta e caminhar progressivamente na direção dos aspectos mais abstratos relativos ao fazer e ao pensar de uma sociedade. É contextualizar histórica e culturalmente uma habitação, um instrumento de trabalho ou marcas deixadas pelo trabalho do homem na paisagem, conjunto de dados que os arqueólogos chamam de "cultura material". É entender a mudança das sociedades, partindo das evidências materiais deixadas pelo trabalho do homem. É relativizar a diferença, no contato com o "outro" presente em artefatos, construções, imagens que, de início, podem surpreender pelo inusitado, mas que depois são compreendidas simplesmente como respostas particulares às mesmas grandes demandas com as quais os homens deparam no cotidiano: a subsistência, a necessidade de expressão do sensível e o contato com a transcendência do viver. Neste sentido, é um subsídio para o exercício da tolerância.

Aprender com as coisas é dar-se conta do papel ativo que elas desempenham na constituição de uma sociedade, ontem e hoje. De como foram e são marcas e sinalizadores na teia de relações sociais que constitui uma cultura. De como podem ser manipuladas para representar ideologicamente grupos sociais hegemônicos. Representa a apropriação da metodologia da disciplina arqueológica em proveito de um ensinar/aprender dinâmico em que o estudante sente-se estimulado a buscar respostas em vez de apenas assimilar conteúdos constituídos através de processos totalmente desconhecidos e cujo sentido e significado não são percebidos.

Significa tornar disponível ao aluno a vivência e a experimentação do processo de construção de um conhecimento a partir da exploração do universo material de uma sociedade: grosso modo, ir do caco cerâmico ao homem, trilhando um caminho no qual a observação, os questionamentos, a proposição e o teste de hipóteses, a avaliação e crítica dos procedimentos impõem-se como método de trabalho. Ao final do processo de investigação o estudante sente-se co-autor do conhecimento produzido; percebe-se como potencialmente sujeito ativo no processo de aprendizado.

Em síntese, foram essas as reflexões que inspiraram o nosso Projeto. Por outro lado, as múltiplas questões históricas, arqueológicas e patrimoniais, suscitadas pelo monumento, forneceram o conteúdo e tornaram-se o núcleo articulador das ações educativas desenvolvidas ao longo deste processo.

\section{A implementação do Projeto}

\section{i. Os professores e as atividades de formação}

A ação educativa, a partir do primeiro semestre de 2001, iniciou-se após contatos com a direção e professores da escola pública Profa. Gracinda Maria Ferreira, "vizinha de muro" do sítio arqueológico, visando o planejamento e a realização de uma série de atividades preparatórias de informação sobre conteúdos e objetivos do Projeto. Por tratar da disciplina arqueológica e de questões relativas ao patrimônio histórico, áreas de conhecimento que não integram o universo das disciplinas usualmente tratadas na escola fundamental e média, o Projeto só seria viabilizado se os docentes estivessem familiarizados com as noções básicas pertinentes a estes campos de estudo. ${ }^{3}$

(3) Como ampliação da ação educativa na escola, propôs-se trabalhar com públicos diferenciados. Assim sendo, em 2001, contatamos o grupo de terceira idade "Reviver", do SESI de Santos, coordenado por Renata Fuentes, e aplicamos a atividade "Patrimônio Cultural e Memória: a Terceira Idade e o MAE/USP”. Na primeira visita realizada pela educadora Judith Mader Elazari à sede do grupo localizada no mesmo bairro que abriga as ruínas do Engenho São Jorge dos Erasmos, foram apresentadas e debatidas questões relacionadas ao patrimônio cultural, memória, e a necessidade da preservação dos bens considerados culturais. Os componentes do grupo tiveram oportunidade de manusear objetos arqueológicos e trocar idéias sobre o trabalho do arqueólogo e sua importância. No 


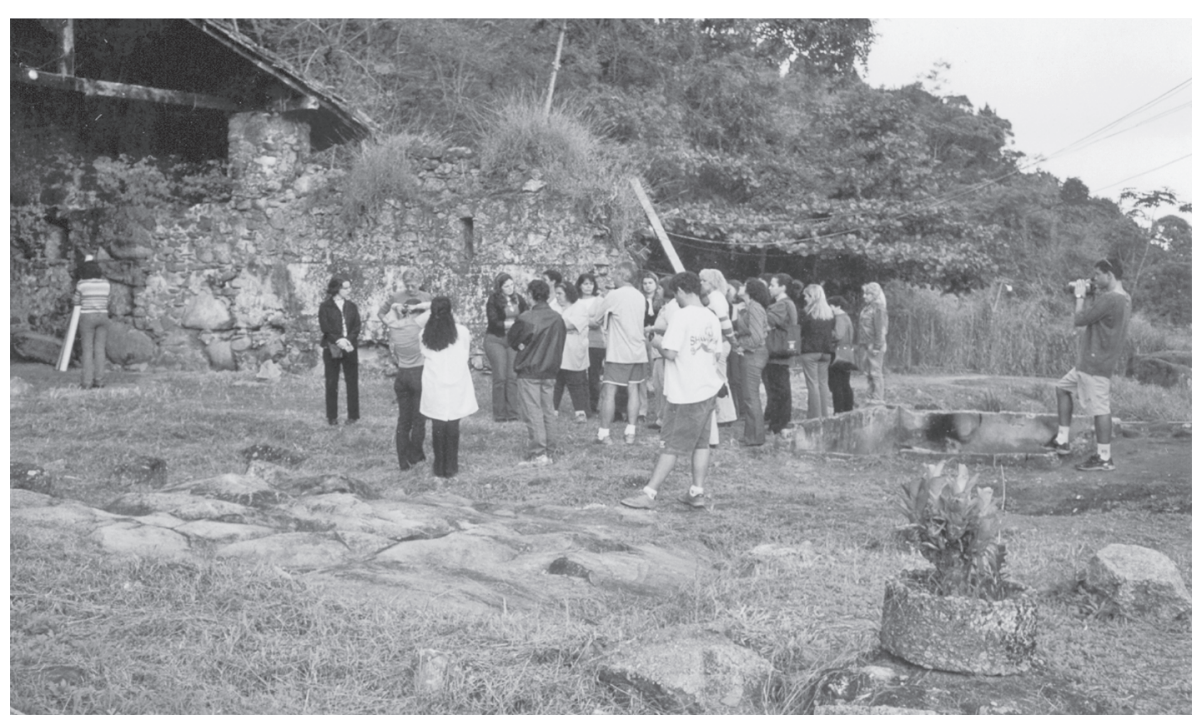

Foto 2. Atividade com professores no Engenho. Imagem: Elaine F.V. Hirata.

Assim, realizou-se inicialmente um Workshop cujo fundamento era provocar o debate de questões básicas relativas à metodologia da arqueologia, aos conceitos de cultura e patrimônio cultural. Esta atividade usou de um recurso que seria posteriormente empregado no trabalho com os alunos: o contato e manuseio orientado de alguns objetos arqueológicos. Desta maneira os professores experimentaram a prática pedagógica que seria, posteriormente, a base do desenvolvimento do Projeto: a exploração do documento material como forma de estímulo ao aprendizado (Foto 2).

Dando continuidade ao processo de formação dos professores, foi organizada uma disciplina de extensão universitária intitulada

segundo contato com o grupo, os componentes levaram objetos significativos em suas vidas, contextualizando-os aos participantes em debate sobre a memória individual e memória coletiva. No terceiro encontro foi montada uma exposição dos objetos debatidos anteriormente. As pessoas puderam compreender através de suas próprias ações como os conhecimentos construídos a partir de objetos que fazem parte da cultura material de um grupo são socializados através de uma exposição. E como síntese destes encontros, o grupo esteve no MAE USP, para uma visita orientada à exposição "Formas de Humanidade" e participaram de uma oficina da memória, relacionando as atividades desenvolvidas em Santos e no Museu.
Arqueologia: uma experiência educativa junto ao Engenho São Jorge dos Erasmos, com a presença de trinta professores da escola. As atividades envolveram aulas teóricas, seminários, leituras e discussões de textos e, como trabalho de campo, uma visita de reconhecimento e estudo das ruínas do Engenho. Embora atuando em área contígua ao monumento, a maioria dos professores e alunos não o conhecia. Neste momento foi possivel vivenciar uma dimensão fundamental da prática arqueológica ou seja a pesquisa no terreno, que envolve além da escavação em si, a percepção da paisagem e a integração entre o ambiente natural e o ambiente construído. Como trabalho final de avaliação, os professores elaboraram, em grupo e a partir das temáticas discutidas em aulas, projetos a serem implementados na escola. Baseando-se nestes resultados, a equipe do MAE, em parceria direta com cinco professores da Escola, além de outros educadores interessados, elaborou um projeto único, para dois anos, a ser desenvolvido com sete classes de $7^{\mathrm{a}} \mathrm{e} 8^{\mathrm{a}}$ série do ensino fundamental e $1^{\circ}$ ano do ensino médio, com as quais esses professores já trabalhavam. ${ }^{4}$

(4) Participaram desta fase os professores: Andrea Candeia, Andrea Lousada S. Simões, Carmen Lucia D. Guimarães, Lilian Gonçalves de Oliveira e Maria de Fátima L.P. Miziara. 


\section{ii. O Projeto na Escola}

No ano de 2002 o Projeto foi introduzido na Escola através de inserção nos programas desses professores. A interdisciplinaridade começou a ser construída através da discussão da temática básica no espaço de disciplinas diferentes: História, Geografia, Ciências, Matemática e Português. Os artefatos, entendidos como documentos materiais e veículos de comunicação e expressão, constituíam, ao lado do documento material principal, o Engenho, um fio condutor perpassando transdisciplinarmente os conteúdos particulares. Paralelamente ao desenvolvimento do Projeto pelos professores, a equipe do Museu elaborou um conjunto de materiais pedagógicos de apoio ao trabalho docente, que se integraram no que foi chamado "kit" de documentos materiais e iconográficos do Engenho São Jorge dos Erasmos.

Este tipo de artefato pedagógico já vinha sendo utilizado, com bons resultados, em projetos educativos em andamento no Museu de Arqueologia e Etnologia da USP desde 1989 (Hirata et al. 1989). Evidentemente o "kit" planejado para o Projeto voltado ao Engenho amealhou a experiência acumulada em todos estes anos e, como principal incorporação, deve-se apontar a inclusão de um vídeodocumentário que, como se verá no decorrer deste artigo, acabou por se constituir em uma rica experiência na aplicação da linguagem audiovisual à educação. ${ }^{5}$

\section{iii. Material didático básico: o "kit" de docu- mentos materiais e iconográficos}

A elaboração do "kit", desde suas primeiras versões, significava uma estratégia para promover a experimentação e a exploração dos artefatos, antigos e contemporâneos, como via de aprendizagem em sala de aula. $\mathrm{O}$ contato com o mundo material, como já foi enfatizado

(5) Este "kit" será levado à Secretaria de Educação de Santos e posto à disposição para empréstimo a professores interessados, após preparação dos mesmos por equipe de pedagogos ligados a esta instituição. inicialmente neste artigo, faz parte do cotidiano das pessoas, mas os objetos "antigos" muitas vezes assumem, aos olhos dos visitantes, nas instituições que detêm a sua guarda, um alto grau de estranhamento ou distanciamento daquilo que se constitui na experiência de vida de cada um. Não são vistos como documentos de uma época, produtos do trabalho de indivíduos semelhantes ao homem atual, mas sim como expressões, seja do "diferente absoluto" ou do "refinamento perdido e a ser buscado", enfim toda uma gama de representações associadas aos "objetos de museu". O "kit", por outro lado, ao levar os artefatos à sala de aula promove, por meio da mediação do professor, uma "desconstrução" desses significados equivocados e introduz os significados originais que remetem à produção, uso e descarte de um objeto (Elazari 2000).

O conjunto, concluído em 2002, passou a ser utilizado em sala de aula pelos professores. Embora apresentando documentos relacionados ao passado, este "kit" é também um instrumento que abre a perspectiva de uma reflexão fundamentada e crítica sobre o presente: no tempo e no espaço, os artefatos são produtos do trabalho do homem, em outras palavras, são parte da história da humanidade e passam a compor um universo concreto a ser vivenciado pelos que os manuseiam, observam, interpretam, enfim, os contextualizam. Assim, através do uso deste conjunto didático provocou-se um novo estímulo ao exercício da aprendizagem, propiciando ao estudante a oportunidade de percorrer uma trajetória análoga à do arqueólogo, construindo o conhecimento a partir da análise de um conjunto de dados sobre o qual serão estabelecidas hipóteses e modelos interpretativos. Como já foi apresentado, o artefato, ao permitir inferências múltiplas sobre os mais variados temas, pode ser um articulador de conteúdos e propiciar o desenvolvimento de habilidades cognitivas importantes que vão desde o estabelecimento de sistemas de classificação a partir da definição de critérios até a percepção dos códigos que servem de sinalizadores culturais em todo tipo de produto material. 
O conteúdo do "kit" (Fotos 3 e 4)

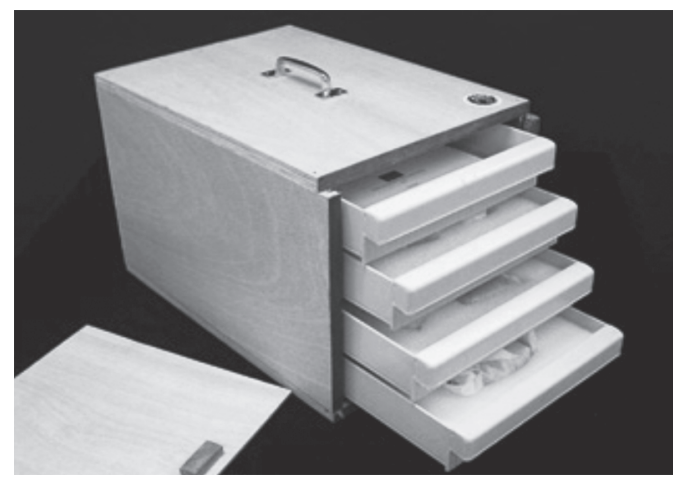

Foto 3. Caixa contendo os materiais pedagógicos de apoio ao professor. Imagem: Wagner Souza e Silva.

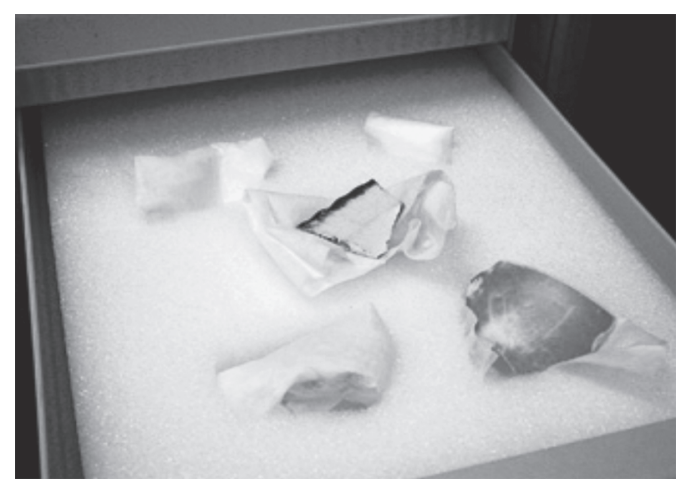

Foto 4. Detalhe de materiais de louça do "kit". Imagem: Wagner Souza e Silva.

- Objetos arqueológicos: de pedra lascada e polida e fragmentos de faiança.

O manuseio orientado desses objetos exercita um conjunto amplo de habilidades das quais destacaremos algumas: habilidades de observação e descrição a partir da constatação de que cada objeto é composto de partes que se inter-relacionam funcionalmente para compor um todo; percepção das diferentes formas e de suas articulações com funções específicas ou com padrões estilísticos próprios de uma época ou lugar; elaboração de sistemas classificatórios assentados em parâmetros tais como matéria-prima, técnica de fabricação, função; elaboração de hipóteses fundamentadas para interpretar um determinado traço pertinente a um objeto ou conjunto deles. Estes materiais foram utilizados em sala de aula de forma sistemática a partir do primeiro semestre de 2003.

- Imagens "de época" relativas aos engenhos de açúcar no período colonial.

Os documentos iconográficos podem ser utilizados para auxiliar na contextualização histórica do Engenho dos Erasmos. Nestas imagens estão presentes cenas da vida cotidiana nos engenhos, a mão-de-obra utilizada, elementos da paisagem, instrumentos de trabalho.

- Video Engenho dos Erasmos Imagens da Redescoberta ${ }^{6}$

- Textos de apoio ao professor e ao aluno.

Este conjunto é composto por textos que discutem o conceito de cultura, patrimônio cultural e arqueologia; relato histórico sobre o Engenho dos Erasmos; textos sobre tecnologias líticas, cerâmica e faiança.

- Sugestões de atividades pedagógicas para cada um dos componentes do conjunto.

Buscam orientar o professor no uso dos diversos materiais e também o incentiva a criar novas formas de aproveitamento dos recursos.

- Roteiro para o registro das atividades a serem desenvolvidas.

Este roteiro para o registro das atividades pretende levar o professor a refletir sobre as estratégias utilizadas em cada etapa da execução do projeto pedagógico.

- Sugestão de avaliação do uso do conjunto.

(6) Sobre a elaboração do vídeo, ver adiante o tópico Os recursos audiovisuais na estratégia da ação educativa. 
A idéia é propor aos professores que façam a avaliação do trabalho juntamente com os alunos, para que ambos os lados possam perceber os avanços e as dificuldades e assim seja aberta a possibilidade de aperfeiçoamento deste trabalho.

\section{iv. Explorando as ruínas do Engenho}

O trabalho com o "kit" foi também uma sólida preparação para uma etapa intensiva de visitação dos alunos ao Engenho. Nesta etapa de reconhecimento do sítio arqueológico foram organizados grupos com cerca de 20 alunos que percorreram as ruínas orientandose pelas informações visuais de uma planta baixa da área, baseada nas escavações arqueológicas realizadas em 1996 (Andreatta 1999; Anjos 1998). Os grupos elaboraram relatórios de observação a partir de diretrizes definidas previamente. Como produto final destas visitas, foi organizado um evento aberto a todos os alunos em que os grupos apresentaram dramatizações cujos temas se relacionavam com o Engenho (Foto 5).

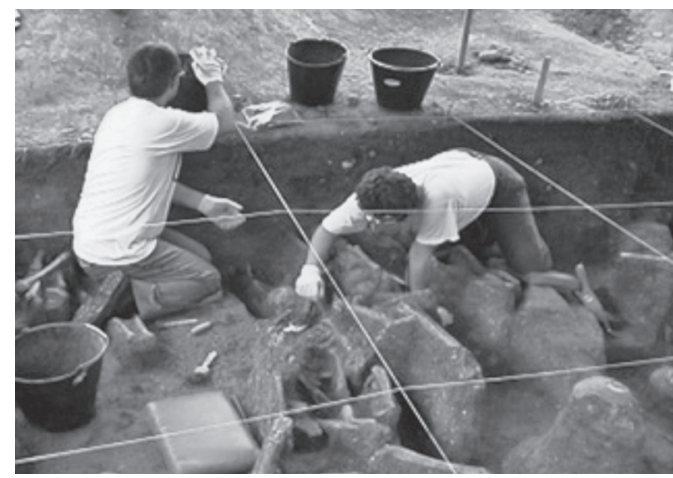

Foto 5. Vista das escavações do sítio Engenho dos Erasmos em 2003. Imagem: Silvio Cordeiro.

Em 2003, com o reinício das escavações arqueológicas, várias classes voltaram a visitar o sítio arqueológico. Desta vez tiveram a oportunidade de ouvir os arqueólogos presentes em campo descrevendo o seu trabalho e escavando. A partir dessas experiências, "muito ricas", segundo os depoimentos dos alunos e professores, surgiram novas propostas de ação, inclusive a construção de um sítio arqueológico experimental na área da Escola, para que toda a complexidade e riqueza do trabalho envolvido em uma escavação arqueológica pudessem ser mais vivenciadas e compreendidas.

\section{v . Sítio Arqueológico Experimental: um exercício interdisciplinar de aprendizagem, um convite para o olhar}

O que é um sitio arqueológico? Podemos dizer que se trata de um local demarcado pelos arqueólogos para evidenciar e analisar os vestígios deixados por uma ocupação humana do passado. A variedade de sítios é tão grande quanto a diversidade de épocas e de culturas na história da Humanidade (Meneses, s/d; Neves 1995).

Entretanto, para o desenvolvimento de uma técnica ou a observação controlada de algum material específico, os cientistas podem simular um sítio arqueológico, isto é, criar uma área ou sítio de escavação experimental. Quando utilizado como recurso pedagógico, esse tipo específico de sítio oferece a oportunidade de descobertas tanto para alunos como para professores, como pudemos verificar em nossa ação educativa.

Os estudantes são estimulados a praticar o seu senso de observação, organização e responsabilidade. Pela exposição a questões de ordem prática, inerentes à atividade, eles refletem sobre sua própria aprendizagem, pois deparam com o inevitável: como vou fazer, como posso resolver?...

O desafio concreto expõe o estudante a uma situação que o faz perceber como está dirigindo o foco do seu próprio olhar, ou seja, da sua atenção, pois as soluções de problemas desse nível dependem, de fato, do que foi aprendido nas diversas disciplinas, numa combinação criativa. Exposto ao "fazer", cada estudante é levado a perceber a singularidade do ritmo pessoal que emprega nas suas associações e conclusões. 
Para os professores, essa experiência demanda um cuidadoso planejamento sobre a melhor maneira de se elaborar o conteúdo programático, para que os objetivos cognitivos possam caminhar juntos. Um sítio arqueológico experimental, por ser uma atividade ao ar livre, vem ampliar a curiosidade e facilitar a receptividade dos estudantes. Estes jovens, acostumados à apresentação do conhecimento como algo fracionado em matérias curriculares, são convocados a tecer suas hipóteses, elaborar explicações. Por isso, o aspecto interdisciplinar dessa vivência é, certamente, um dos seus pontos-chave.

Mas o trabalho com um sítio arqueológico experimental não se esgota no exercício de escavação. Na verdade, é um conjunto de etapas que compõem o sentido da vivência. Tão importante quanto o tempo passado nas quadras de escavação é o dedicado ao levantamento de hipóteses, ou ainda, ao registro, análise e a comunicação dos resultados. A avaliação também é uma etapa do trabalho, e ela passa a ser a oportunidade de o aluno registrar o seu próprio caminho de aprendizagem.

Assim, a reflexão e discussão sobre alguns conceitos deverão preceder o início do trabalho com os alunos e até mesmo a etapa de organização do sítio, propriamente dito. Entre elas se destacam:

- O que é Cultura?

- O que é Cultura Material?

- Qual a importância do Método em uma Pesquisa Científica?

- Qual a diferença entre Cavar e Escavar?

- Quais as etapas de trabalho do arqueólogo?

A profundidade e a clareza sobre essas questões são fundamentais aos educadores envolvidos na experiência de um sítio experimental, pois é a partir da compreensão desses conceitos que eles refletirão sobre o caminho que o olhar do aluno percorre no processo de aprendizagem, vista como construção do próprio conhecimento. Propusemos aos professores da Escola Estadual Gracinda Maria Ferreira, que ousassem e realizassem um sítio arqueológico experimental, com a nossa assessoria. Posto em prática o exercício, pudemos confirmar, segundo o exposto, que ela enriqueceu todos que participaram estudantes e professores.

\section{Qual o tipo de sítio a fazer?}

Diferenciamos dois tipos de sítio experimental:

Sítio arqueológico experimental artificial: chamamos assim o modelo em que o local da escavação seria preparado especialmente pelos organizadores com objetos selecionados e enterrados em uma determinada ordem, para que os alunos, escavando, os encontrassem.

Sitio arqueológico experimental natural: nesse caso, não existiria controle sobre o que seria achado. A escolha da área da escavação é que serviria de parâmetro às hipóteses sobre o tipo de material que poderia ser encontrado.

Os dois tipos de sítios possibilitam interessantes recortes dos programas das diversas séries, em relação ao conteúdo específico e também aos temas mais gerais, ligados a conquistas comportamentais (Almeida 2002). Para o nosso projeto piloto escolhemos montar um sítio arqueológico experimental natural. Foi discutido que os alunos, após um preparo, iriam delimitar as quadras, escavariam e teriam o desafio de registrar tudo o que encontrassem. A observação contaria com a atenção dos professores, que, por sua vez, teriam preparado questões ligadas aos programas da série (Foto 6).

Sabíamos que a área que nos foi designada para a atividade era exposta ao descarte de pequenos objetos de uso cotidiano, como tampinhas, canetas, papel de doce etc.. Achamos que isso seria um bom estímulo para uma reflexão sobre o nosso próprio cotidiano. No 


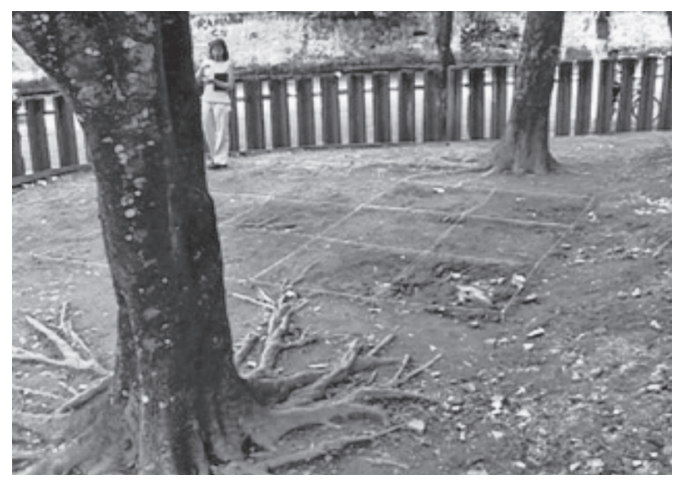

Foto 6. Área do terreno da escola preparada como sitio arqueológico experimental. Imagem: Silvio Cordeiro.

planejamento, tivemos o cuidado de deixar a experiência para um período de raras possibilidades de chuva (no nosso caso, entre setembro e outubro), pois um solo molhado pode inviabilizar o exercício.

A preparação do terreno demandou apenas uma rápida limpeza e atenção quanto aos muitos formigueiros. Essa providência, absolutamente corriqueira e natural, marcou uma mudança na percepção que os alunos tinham sobre aquele próprio espaço da escola, pois estavam acostumados a ele apenas com distância e desinteresse, enfim, uma área sem significado (Fotos 7 e 8 ).

O "aparecimento" da área depois de limpa e o trânsito de objetos absolutamente incomuns para aula (baldes, grandes peneiras, trenas, pás, colheres de pedreiro...), acabou por aguçar a curiosidade também das classes e séries que não estavam envolvidas com o projeto. Isso

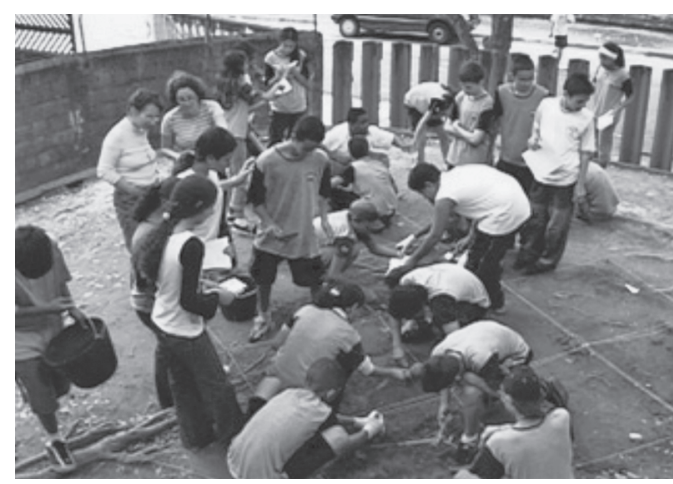

Foto 7. Estudantes iniciam a escavação do sitio arqueológico experimental. Imagem: Silvio Cordeiro. motivou um interesse que, de fato, não havíamos planejado conquistar.

\section{A experiência}

Com a decisão de fazer o sítio experimental, deparou-se com uma série de questões de múltipla escolha, que, ao invés de terem uma única resposta correta, sugeriam uma série de alternativas possíveis para serem ponderadas.

Assim, o nosso ponto de partida foi:

Quais os professores que participariam? Isso foi definido segundo as possibilidades de carga horária na escola, grau de interesse pessoal e a compreensão da vinculação possível entre o conteúdo que estavam trabalhando com suas classes e as possibilidades do exercício. Essa definição foi fundamental para organizarmos a atividade, uma vez que, só a partir dela, é que tivemos o número de educadores envolvidos e as matérias que seriam abordadas objetivamente.

Quais as classes que iriam trabalhar com o sítio experimental? Com essa escolha, definimos a idade dos educandos e quais os conteúdos específicos que seriam privilegiados durante a experiência.

Qual o tempo disponível para o trabalho? Foi importante organizá-lo em semanas e horasaula para que a divisão das várias etapas do projeto fosse respeitada.

Qual o local que a escola poderia deixar disponível para a experiência? Para essa decisão foi fundamental a aprovação e o engajamento

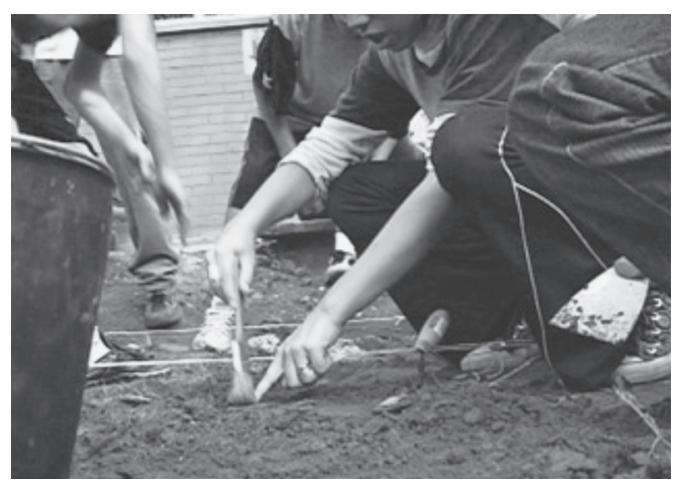

Foto 8. Escavação do sitio arqueológico experimental. Imagem: Silvio Cordeiro. 
da diretoria da escola, pois a área ocupada pelo sitio ficaria isolada durante o período da atividade.

O grupo de organização do sítio experimental foi formado por quatro professoras entusiasmadas, responsáveis pelo ensino de Matemática, História, Ciências e Geografia.(7)

A classe escolhida foi uma sétima série que já havia participado de atividades ligadas à Arqueologia e ao Engenho dos Erasmos. A idade dos estudantes envolvidos variava entre 12 e 14 anos. O perfil do grupo, segundo as professoras, era participativo e produtivo.

Tirar o aluno da sala de aula, onde cada um tem o seu espaço definido assim como uma postura previamente combinada como ideal (isto é, sentada), exige dos organizadores um cuidado especial. Pensando nisso, as professoras elaboraram e discutiram com a classe um código de compromissos, que incluía algumas regras de comportamento, cuidado e organização do material que iria ser manipulado.

Cada professora organizou o núcleo de conteúdo que seria trabalhado objetivamente, segundo o programa anual da série. Em Matemática, por exemplo, privilegiou-se o tema de áreas, perímetros e estatística. Em Ciências os tipos de solo, a classificação vegetal e de espécies de insetos. A professora de História optou pelo tema: "metodologia do trabalho científico" e a de Geografia "ambiente e sociedade de consumo".

Durante a escavação, a atitude dos alunos foi entusiasmada e, apesar da excitação, não houve nenhum problema de disciplina e as etapas seguintes também foram realizadas com interesse.

Depois da avaliação foram registradas algumas impressões das professoras que realizaram o trabalho, em uma reunião com outros professores da escola, são elas:

"O aluno se coloca não apenas como receptor do conhecimento, mas como produtor do conhecimento".

(7) As professoras Lilian G. de Oliveira, Andrea Candeia, Carmen L. D. Guimarães e Andrea L. S. Simões.
"Quando se começa uma atividade assim, não se sabe como exatamente ela vai terminar".

"Comparando classes que não trabalharam com o projeto e classes que já trabalharam, essas últimas têm atitudes completamente diferentes quanto à noção de como se produz o que se conhece".

"Um artefato instiga a curiosidade do aluno, que a partir dele passa a ocupar o papel de criador do seu conhecimento".

"O projeto facilitou a aproximação de áreas muito distantes com a das ciências exatas e a das ciências humanas".

"Os resultados que tivemos até aqui foram visiveis, principalmente na mudança de atitude dos alunos".

"Professores de disciplinas diferentes trabalhando juntos"!

De fato, a escavação propiciou a oportunidade de os alunos questionarem a visão de que o conhecimento seria algo compartimentado em gavetinhas das diversas disciplinas. Como um holograma, a experiência do sítio arqueológico, permitiu que, ao mesmo tempo, se percebesse o aprender e o saber tanto pelos alunos quanto pelos professores que dela participaram.

\section{vi. Os recursos audiovisuais na estratégia da ação educativa}

As diversas formas de utilização do vídeo no projeto educativo constituíram, no seu conjunto, um processo de produção videográfica que possibilitou tanto a experimentação pedagógica, junto aos estudantes e professores, quanto a documentação e o registro da própria pesquisa arqueológica e histórica sobre o

Engenho. Vale aqui apontar que a produção videográfica desenvolvida neste contexto tornase instrumento direto aos propósitos gerais da chamada divulgação científica, comunicando através da narrativa audiovisual conteúdos acadêmicos ao público de maneira mais ampla.

Os recursos audiovisuais foram assim inseridos na composição de uma metodologia educativa experimental sob a forma de Oficina de Vídeo com estudantes da escola vizinha ao 
monumento, a qual gerou o videodocumentário Engenho dos Erasmos: Imagens da Redescoberta.

Assim, a produção de conteúdo audiovisual sobre o Engenho no contexto da Oficina propiciou a integração de estudantes e moradores da comunidade local à discussão do valor do monumento como patrimônio histórico. As técnicas audiovisuais apropriadas pela construção de uma narrativa que fosse fruto do desenvolvimento das pesquisas e do conjunto das ações didáticas permitiram que o vídeo se revelasse um instrumento valioso na mediação entre o conhecimento científico, a comunidade local e um público mais amplo.

Esta diversidade de usos permitiu que se criassem novas possibilidades de apropriação das práticas videográficas no diálogo com a arqueologia e a educação. Neste sentido, o projeto abriu, através da experiência audiovisual, um campo até então imprevisto de produção de conhecimento prefigurado pelo diálogo com o instrumental da comunicação.

\section{O vídeo na ação educativa: imagens $d a$ redescoberta}

No contexto de nossa ação educativa ampliamos o potencial do vídeo enquanto meio propício ao envolvimento de jovens em atividades educativas. $\mathrm{O}$ usufruto do vídeo no projeto permitiu que um grupo de 12 alunos da escola pública vizinha participasse da Oficina de Vídeo - coordenada por Silvio Cordeiro e André Costa, ambos do grupo de estudos audiovisuais Olhar Periférico (Foto 9).

A Oficina buscou motivar os jovens na busca do conhecimento histórico sobre o monumento e da reflexão sobre seu sentido atual na comunidade. Este foi o contexto mais amplo que permeou a elaboração do videodocumentário Engenho dos Erasmos Imagens da Redescoberta, em 2001/2002.

$\mathrm{Na}$ época, o objetivo geral da Oficina de Vídeo foi assim exposto:

\section{(...) promover a redescoberta das} ruínas através da educação do olhar, permitindo que se ultrapassasse o tom contemplativo e o reconhecimento do

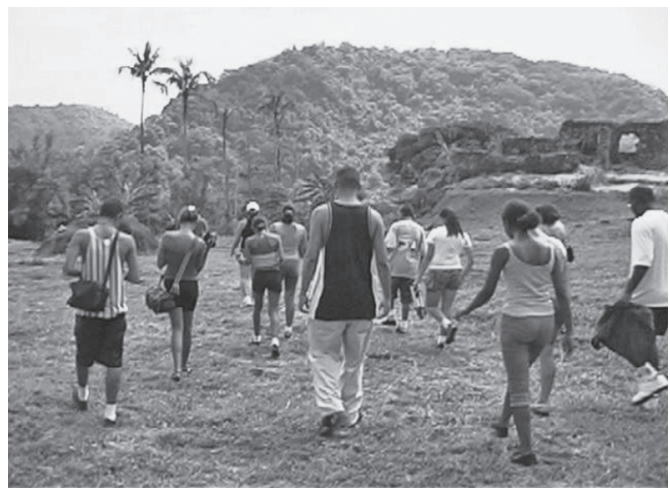

Foto 9. Estudantes da oficina de vídeo entram pela primeira vez no Engenho dos Erasmos. Imagem: Olhar Periférico.

monumento apenas enquanto vestígio de um passado remoto; indo além, busca-se através da oficina com esses jovens o despertar de um olhar curioso e crítico, que desvende as narrativas por trás do objeto arquitetônico, possibilitando uma amplitude de compreensões e questionamentos acerca da história do lugar onde moram. (Cordeiro e Costa 2001: 323).

Tal ação situou-se na perspectiva de despertar a comunidade para uma nova leitura e percepção da paisagem humana do lugar, a partir do sítio arqueológico e entorno do engenho, relacionando-o ao conjunto das evidências históricas da região da Baixada Santista, enquanto vestígios de outros cenários sociais e econômicos, bem como ao contexto transatlântico do comércio do açúcar, nos séculos XVI e XVII. Assim, no contexto geral do projeto, a produção audiovisual foi incorporada enquanto processo de estímulo ao aprendizado e envolvimento de pessoas na construção do conhecimento sobre o próprio lugar que habitam, ou seja, no entorno de um sítio arqueológico histórico, bem valorizado nas instâncias culturais do Brasil, entretanto, pouco conhecido pela própria comunidade, na época da realização da Oficina de Vídeo (Foto 10).

Além de se justificar como um estímulo lúdico de estratégia educativa, por que ensinar 


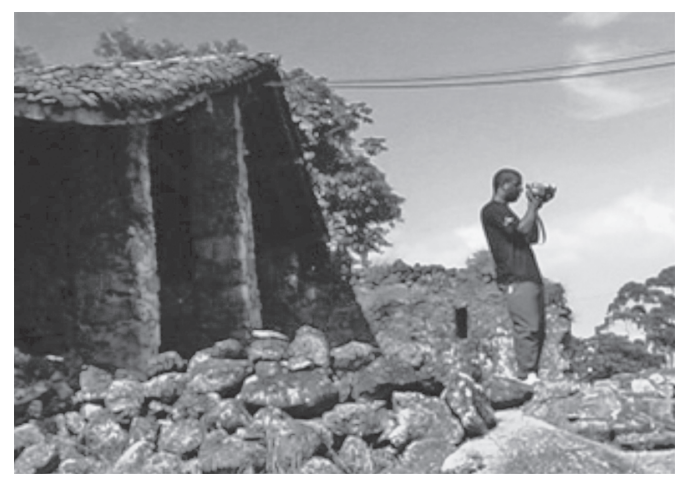

Foto 10. Estudante grava imagens durante exercício nas ruínas do Engenho dos Erasmos. Imagem: Olhar Periférico.

os conceitos básicos da linguagem videográfica aos alunos se o que nos interessa, como disciplina, é a História e a Arqueologia? O fato é que é com a linguagem que reconhecemos o mundo. É por meio dela que pensamos o mundo. Há nesta proposta pedagógica, portanto, uma intenção de renovar em cada aluno a linguagem pela qual ele vê e compreende o fato histórico. Sendo a linguagem audiovisual um conjunto de códigos de representação novo a esses estudantes, olhar o sítio e representá-lo através de uma câmera recria um universo novo de relações e de formas de pensar os objetos e os eventos históricos. Olhar o sítio arqueológico através de uma câmera significa operar com estes conceitos de representação, que nos deslocam enquanto observador, conferem novos desafios à nossa compreensão e nos acionam em direção a este lugar que é o nosso objeto de estudo no momento.

A perspectiva pedagógica das atividades educativas na oficina fora sempre, portanto, a do exercício do olhar. Praticar o olhar que identifica, reconhece, classifica, ordena. Experimentar o olhar que renova nosso conhecimento, explora novas possibilidades de relação entre os objetos, o ambiente construído, a paisagem natural. Desenvolver o olhar que comunica, que representa a história que está diante de nós para que possa ser por nós mais bem compreendida, e para que possa ser compartilhada.

Assim é que o vídeo se insere neste projeto: além de permitir uma série de produ- tos didáticos audiovisuais que transportam o sítio arqueológico para a sala de aula, o vídeo fora neste caso apropriado como processo. $\mathrm{O}$ processo de produção de vídeo permeia os processos ensino-aprendizagem e as possibilidades de construção do conhecimento a partir desta troca se multiplicam (Foto 11).

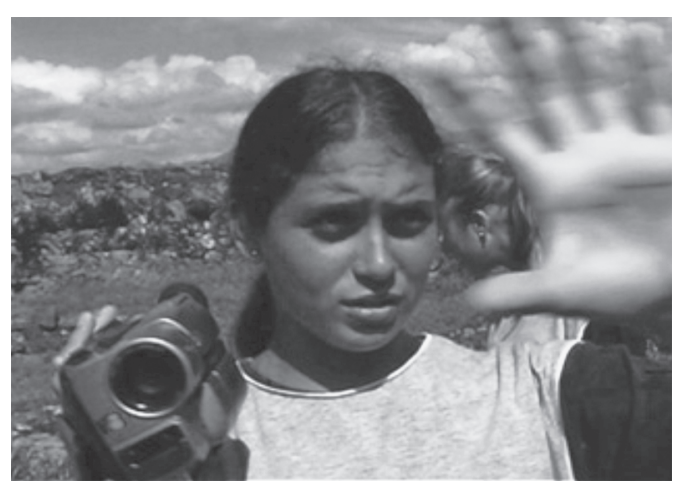

Foto 11. Estudante estuda enquadramento durante exercício nas ruínas do Engenho dos Erasmos. Imagem: Olhar Periférico.

Em tempo, as diversas atividades da Oficina junto aos estudantes possibilitaram a constituição de um amplo acervo de referências, que se conectam no âmbito de vários estudos, interligando disciplinas estudadas na escola. No desenvolvimento de novas maneiras de articular a produção do conhecimento científico com a participação comunitária, o vídeo, neste sentido, revelou-se uma estratégia importante além da difusão cientifica, abrindo possibilidades à investigação e ao processo pedagógico que estimula a apropriação social da pesquisa acadêmica, provocando o envolvimento social, que compreende, por sua vez, iniciativas diversas e interdisciplinares.

É importante notar que o vídeo Engenho dos Erasmos - Imagens da Redescoberta tem alcançado públicos amplos em escolas, projetos de capacitação em audiovisual para professores da rede pública, como o Projeto Cinema e Vídeo Brasileiro nas Escolas, da Ong Ação Educativa. Tem sido exibido muitas vezes acompanhado de palestras ou debates com os realizadores em torno das possibilidades de uso do vídeo como instrumento pedagógico. 
Acreditamos que a experimentação realizada na Oficina de Vídeo abriu a perspectiva ao desenvolvimento de uma metodologia de trabalho educativo e de difusão do conhecimento que nos parece bem promissora.

\section{Considerações finais}

Ao final destes anos é possivel um distanciamento crítico que permite a análise do que significou este Projeto, em primeiro lugar, para um grupo de especialistas que saem da universidade e buscam aproximar-se do universo da educação pública através da discussão do que é patrimônio cultural e de quais seriam as vias de apropriação deste bem pela comunidade. Neste processo paralelo e dinâmico de difusão de idéias oriundas do meio acadêmico e de incorporação de demandas de professores e alunos, foi possivel a instituição experimental de uma prática pedagógica inovadora,motivadora e participante. Os artefatos, a paisagem, os homens, e especialmente as relações entre eles, foram pouco a pouco se constituindo em eixos articuladores de temáticas e conteúdos de diferentes disciplinas. O Engenho foi apenas o ponto de partida (Hirata et al. 2001).

A primeira vitória concreta do projeto foi percebida quando os professores - poucos, é verdade - dele se apropriaram e muitas vezes, de maneira totalmente independente, o conduziram de forma a produzir um resultado original. É o que foi possível observar nas discussões conceituais prévias e posterior implantação do sítio arqueológico experimental, atividade que acreditamos ter sido a síntese final do Projeto.

A integração de disciplinas pôde ser efetivada nos vários momentos que envolveram a preparação do sítio experimental e, verdadeiramente exercitada no "trabalho de campo". Os relatórios dos alunos registraram a experimentação de uma forma de aprender integrada: a matemática, por exemplo, fundamentando medidas que eram mobilizadas na avaliação de um espaço que, porquanto socialmente ocupado exibia as marcas da passagem do homem, mas que era examinado ao mesmo tempo como o cenário biogeográfico dado e modificado pela ação antrópica. $\mathrm{O}$ mesmo processo de apropriação ocorreu na oficina de vídeo. Neste caso os alunos foram os agentes principais na produção de um discurso audiovisual que, do Engenho, partiu para uma discussão do sentido da preservação do bem cultural e de seus significados para a comunidade. Ao mesmo tempo, e pouco a pouco também os alunos se apropriaram, experimentalmente, de uma nova linguagem como forma de expressão.

A vivência da Oficina de Vídeo foi marcante para os alunos que dela participaram: saídos da escola, anos depois ainda permaneceram fortemente interessados na experiência, mantendo contato com os vídeo-educadores com vistas a novos projetos. O Projeto veio a consolidar uma perspectiva de ensino-aprendizagem que se inspira na própria metodologia da pesquisa arqueológica para propor alternativas pedagógicas centradas na experimentação do universo das coisas. Por outro lado, representou uma interessante experiência de atuação junto a uma comunidade - no caso escolar e ao mesmo tempo vizinha - que tem no seu entorno um monumento histórico.

Uma vertente do Projeto inicial que, por motivos diversos não foi implementada, previa uma pesquisa com os moradores mais antigos e os atuais com vistas ao imaginário construído em torno das ruínas do Engenho. As variáveis que escapavam ao controle dos professores da escola e dos educadores do MAE representaram, sem dúvida, um dos principais entraves ao andamento das atividades.

Assim, questões burocráticas da escola que dificultavam o afastamento dos professores de sua rotina de trabalho para dedicar-se mais ao Projeto, mudanças no corpo de professores e na direção da escola criaram certas descontinuidades na ação proposta. O balanço final, no entanto, aponta para uma resposta positiva tanto dos professores quanto dos alunos quando uma alternativa pedagógica inovadora se apresenta. Os professores e alunos que participaram deste Projeto terão, com certeza, para sempre, a convicção de que ensinar e aprender a partir do mundo das coisas é uma experiência que aproxima a escola da vida. 
HIRATA, E.F.V.; ELAZARI, J.M.; MORITZ, J.; COSTA, A.; CORDEIRO, S.

Exploring Archaeology: an educational project at the São Jorge dos Erasmos sugar mill. Revista do Museu de Arqueologia e Etnologia, São Paulo, 17: 419-433, 2007.

Abstract: This article presents the educational program developed at the archaeological site São Jorge dos Erasmos, a Brazilian colonial sugar mill, and discuss its methodological and conceptual principles.

Keywords: São Jorge dos Erasmos sugar mill - Archaeology and Education Video documentary and Education - Brazil Colonization - Sugar.

\section{Referências bibliográficas}

ALMEIDA, M.B.

2002 O Australopiteco Corcunda. As Crianças e a Arqueologia em um Projeto de Arqueologia Pública na Escola. Tese de Doutorado. Universidade de São Paulo, FFLCH, São Paulo.

ANDREATTA, M.D.

1999 Engenho São Jorge dos Erasmos. Propospecção Arqueológica, Histórica e Industrial. Revista da USP, São Paulo, 41: 28-47.

ANJOS, M.F.

1998 Engenho São Jorge dos Erasmos. Uma abordagem interdisciplinar do documento na Arqueologia Histórica. Dissertação de Mestrado. Universidade de São Paulo, FFLCH, São Paulo.

CORDEIRO, S.; COSTA, A.

2001 Engenho São Jorge dos Erasmos Imagens da Redescoberta. Revista do Museu de Arqueologia e Etnologia, São Paulo, 11: 323-325.

ELAZARI, J.M.

2000 Recursos pedagógicos de museus: "kits"de objetos arqueológicos e etnográficos. Revista do Museu de Arqueologia e Etnologia, São Paulo, 10: 351 a 358.

HIRATA, E; DEMARTINI, C.; PEIXOTO, D.; ELAZARI, J.M.

1989 Arqueologia, educação e museu: o objeto enquanto instrumentalização do conhecimento. Dédalo, 27: 11-46.

HIRATA, E.; ELAZARI, J.M.; MORITZ, J. M.

2001 Arqueologia e Educação: uma proposta para o Engenho São Jorge dos Erasmos. Revista do Museu de Arqueologia e Etnologia, São Paulo, 11: 317-322.

MENESES, U.B.

s/d Natureza da Arqueologia e do Documento Arqueológico: Problemas Gerais da Arqueologia Brasileira. Notas de aula. Universidade de São Paulo, Faculdade de Arquitetura e Urbanismo.

NEVES, E.G.

1995 Os Índios Antes de Cabral: Arqueologia e História Indígena no Brasil. In: Silva, A.L.; Grupioni, L.D.B. (Orgs.) A Temática Indigena na Escola, Novos Rumos para os professores de Primeiro e Segundo Graus. Brasilia. MEC/MARI/UNESCO: 171-196. 